\title{
AN OVERVIEW OF URBAN VILLAGE OPEN SPACES AND OUTDOOR THERMAL COMFORT IN MALAYSIA
}

\author{
${ }^{1}$ Pegah Maroofee ${ }^{*},{ }^{1}$ Norhaslina Hassan, ${ }^{2}$ Amirhossein Ghaffarianhoseini ${ }^{2} \&$ \\ ${ }^{3}$ Shin To Amiri \\ (*First author) \\ ${ }^{1}$ Department of Geography, Faculty of Arts and Social Sciences, \\ University of Malaya, Kuala Lumpur, Malaysia \\ ${ }^{2}$ Department of Built Environment Engineering, \\ School of Engineering, AUT University, Auckland, New Zealand \\ ${ }^{3}$ Department of Civil Engineering, Faculty of Engineering and IT, \\ MAHSA University, Malaysia \\ (pegah2615@siswa.um.edu.my, nhaslina@um.edu.my, \\ amirhosein.ghaffarianhoseini@aut.ac.nz) \\ DOI: https://doi.org/10.22452/jati.vol23no2.7
}

\begin{abstract}
The level of the thermal environment in urban villages open spaces plays a significant role in the personal satisfaction of a city. The different weather and climate attributes of countries as indicated by their geographical location and natural conditions directly affect people's behavior and utilization of open spaces. Hence, a naturally cognizant urban structure arrangement should give high preference to the level of comfort ramifications of urban microclimate. This paper provides an overview of urban villages in Malaysia discussing the tropical climate thermal comfort in their open areas. Malaysia still has some traditional urban villages that have not been replaced by contemporary residential projects due to the rapid modernization and urban growth within the city, keeping their design and characteristics. These characteristics affect the level of the thermal environment and the quality of life of the villages' inhabitants. This review should serve as a motive for local authorities to maintain many of the villages' existing characteristics particularly those that help mitigate the UHI effect namely the large proportion of vegetation when faced with the pressure of urban growth. The overview enhances thermal comfort's knowledge and understanding of urban open spaces in tropical climate context amongst stakeholders of urban development.
\end{abstract}

Keywords: thermal comfort, tropical climate, urban village, outdoor spaces, Malaysia 


\section{Introduction}

Over the decades, Kuala Lumpur (KL) has been confronted with an enormous and significant level of urban spatial expansion. It is very much evident that buildings and their surrounding outdoor context are the main constituents of urbanized areas with an immense effect on their occupants and quality of lives. Researchers have long acknowledged urban quality as the overall key term for the understanding of how the relationship between spaces and people works. When urban quality is low, the number of visits to and activities in urban open spaces will also subsequently be less (Gehl \& Gemzøe, 2004). It is, therefore, important to look at the quality of life in urban open spaces in pursuit of a balanced vision for where people want to move to and live in (Carr-Hill, 1992). Researchers learned that good public spaces are responsive to user needs, easily accessible and are meaningful to the community (CarrHill, 1992; Gehl \& Gemzøe, 2004).

The rapid pace of urban transformations experienced by Kuala Lumpur and other tropical cities creates challenges for achieving an outdoor thermal comfort level, which is preferred by the inhabitants. One of the challenges that will be considered in this paper is environmental parameters in the outdoor urban spaces which affect human comfort. In an urban environment, the human thermal comfort of urban microclimate represents the level of satisfaction of inhabitants, which closely relates to perceptions and preferences towards the way people use outdoor spaces. The level of comfort is felt under a 'stable state' which means an acceptable range for thermal comfort based on the ASHRAE standard 55 (2004), formerly known as the American Society of Heating, Refrigerating and Air-Conditioning Engineers. When the temperature rises in the human body more than the standard level according to the state of comfort, human sensation recognizes and reacts to their warm ecological condition (Evans, 1984). This paper provides an overview of the impact of physical elements such as air quality, urban design of outdoor spaces and their arrangement in an environment, which can play an important role in human thermal comfort in urban areas.

\section{Urbanization}

Urbanization and urban development have contributed altogether to the quick change of the Malaysian economy. The rate and way by which development is occurring have caused massive contribution of stress on nature along these lines influencing the prosperity of the urban inhabitant (Salleh \& Ghaffar, 
2000). These anxieties influence the living wellbeing and comfort profiles of the urban occupant and are most extremely felt by the urban council. Having a better living environment for improved urban quality and making new settlements which matches human requirements result in the creation of towns, cities, and villages over time that highlights the needs of their residents based on economics, society, culture, and comfort (M. Shahidan, 2011). Development of urban spaces in larger scales due to rapid urbanization to achieve the requirements and needs of the residents will undoubtedly affect thermal comfort since the microclimate of these areas will be altered by changing the characteristics of the urban spaces. According to Christensen 2005, the process of covering a substantial portion of land space with constructions or impervious pavements is by definition, urbanization (Christensen, 2005). In another word, increasing human-made changes in urbanized growth cause harmful transformations on the natural ecosystem.

Urbanization can be defined as the process of land use transformations while people concentrated in cities and towns based on social modernization (Ren, Wang, Wang, \& Liu, 2015). Through the rapid growth of social and economic development, considerable workforce tends to move from rural to urban-based industrial areas to find new positions and opportunities for a better future life. Recently, the United Nations Department of Economic and Social Affairs (UNPD, 2014) has presented a record that shows a significant increase in urban population throughout the world between the years of 1950 and 2014. For example, 30\% of the world's population was urban in 1950, but this number has increased to $54 \%$ by the end of 2014. From 1990 to 2025, about 2.9 billion new urban populations are expected to move to urban areas globally. Consequently, the human settlement pattern has transformed significantly and an increase of urban economic activities causes the creation of unique negative ecological results such as carbon emission (Al-mulali, Sab, \& Fereidouni, 2012; Wang, Chen, \& Kubota, 2016). Furthermore, in these areas higher temperature 'islands' are established and at the same time temperatures in the central regions of cities have risen in comparison with their rural environments (Radhi, Sharples, \& Assem, 2015). This temperature distinction is what establishes the Urban Heat Island (UHI) effect.

Environmental decline is constantly related to the development and human activities (Elsayed, 2012). Humans made a significant amount of heat over his activities, and they are an important source of its creation emanating from industrial plants, transportation systems, heating ventilation as well as air conditioning systems which are set up for cooling internal environment in buildings (Elsayed, 2012). There is a persistent need to control the results of 
global warming in metropolitan spaces and to pinpoint possible approaches and strategies to respond to climate change properly (Elsayed, 2012). Sani (1991) proposed that the influence of UHI from urban areas is not limited to horizontal temperatures throughout the surface of the earth but also affects the vertical direction by the atmospheric area with far-reaching consequences (Elsayed, 2012). Other studies have also shown that thermal influences of a large city in the world can potentially extend up to $200 \mathrm{~m}$ to $500 \mathrm{~m}$ and more.

\section{Urban Villages and Environment}

The size and shape of the organization of Asian cities have drastically transformed the urban physical and socioeconomic landscapes (Ujang \& Aziz, 2016). Urban population in East Asia, for example, has increased 3\% per year while urban land expansion reached $2.4 \%$ per year. A part of this urban population is "urban village" population. Urban villages, a distinctive product of rapid urbanization and massive rural to urban migration are a universal phenomenon in many cities with strong economic growth (Chung, 2010; Hao, Geertman, Hooimeijer, \& Sliuzas, 2013).

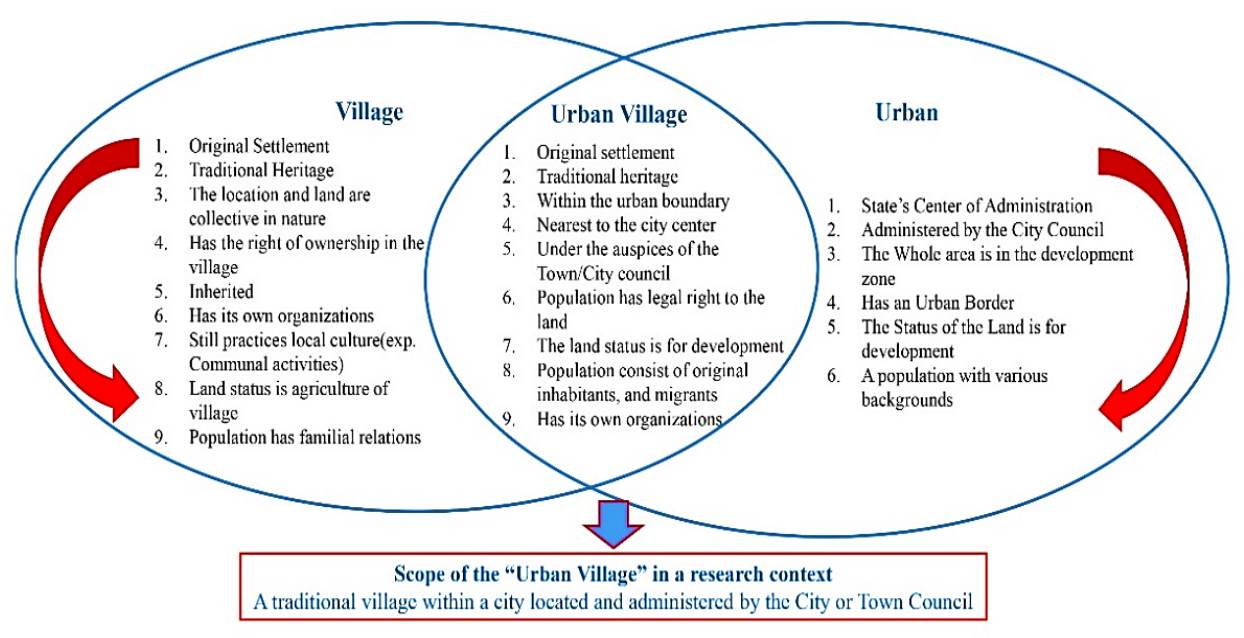

Figure 1: The concept of urban village

(Source: Hao [2015].)

The urban village concept came from the combination of the basic features of the social, physical, and economic environments in the urban and village environments. According to Hao (2015), an urban village is created from rapid urbanization and economic development of cities (Hao, 2015). As Figure 1 
shows, this combination of the village and urban environments' characteristics reveal the basic features of the "urban villages." The formation of the "urban village" environment could be measured through its social (social relations, culture and local traditions as organizational structure), physical (land use, geographical position, its settlement, and construction) and economic (status of the land, the title of land and current socioeconomic activities) areas.

In the context of Malaysia, a kampung is defined as a village or locality with 10,000 or fewer people under the leadership of Village Heads (Ujang \& Aziz, 2016). Malay kampung is modernity's significant other in the contemporary discourse. Observing the rapid globalization and growth in Kuala Lumpur city today, many of the traditional urban villages within and at the periphery of the city have been replaced by residential, commercial, and industrial projects; both small and large scale alike. Perhaps the most discussed urban village in Kuala Lumpur is Kampung Baru sitting in the heart of the metropolitan region. Figure 2 shows examples of urban villages in Malaysia. The sites namely Kampung Baru, Kampung Sungai Penchala, Kampung Melayu Kepong were selected from the identified traditional urban villages in the Kuala Lumpur metropolitan area. These villages hold strong heritage values to the local community and across Malaysia as a whole.

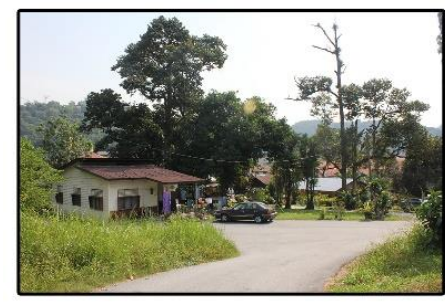

Uraban village 1:Kampung Sungai Penchala

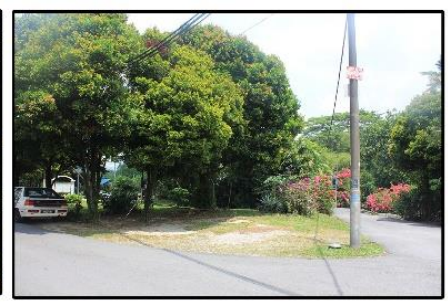

Uraban village 2; Kampung Melayu Kepong

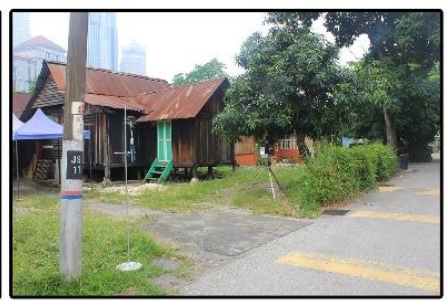

Urban village 3 :Kampung Baru

Figure 2: Urban village 1: Kampung Baru, Urban village 2: Kampung Melayu Kepong and Urban village 3: Kampung Sungai Penchala

(Source: Fieldwork, 2018)

Vernacular architecture and human scale of these urban villages have largely remained, with colorful low-rise wooden detached houses, kitchens, and cafes spilling out onto the streets with large soft-scape percentages, soft ground floor cover, and rich social life. The qualities implied a better microclimatic condition and improved urban quality in some aspects as compared to their urban counterpart. Despite piecemeal development and extension of commercial and residential units, some of the traditional kampungs still look similar to their early years. With the rising land values, 
urban villages have been subjected to real estate development schemes that would maximize the economic potential of the properties. Taking redevelopment steps implies a drastic change in the landscape of urban villages, which will ultimately begin to show UHI characteristics similar to that of the city areas. Another possibility which is related to the current UHI situation and existing literature is that urban villages close to urban developments will be more affected by UHI as compared to those further away. However, the abundance of vegetative cover for shading will reduce the air temperature as compared to the use of buildings for the same purpose with the less vegetative cover in the adjacent urban areas.

There is a relationship between the urban environment and life quality of urban village population. While urban growth and development have affected "urban village" population, the life quality of urban population depends on offered urban and infrastructure services (Saleh, Hashim, Mahat, \& Nayan, 2016). Urban development, therefore, should be considered based on the development of strategies and planning to improve the life quality of urban population including that of the urban village population. The security of life quality and health guarantee the sustainability of a city in a broad realm.

\section{Urbanization and Microclimate}

Christensen (2005) defined the urban climate as the climate in and near urban environments. It is more or less humid, warmer, has more reflected light and shadier than the climate of the nearby land areas. On the other hand, Allaby and Park (2013) defined urban climate as a residential climate affected by the presence of a city that can comprise of lower wind speeds, lower relative humidity, and higher rainfall (Allaby \& Park, 2013). Therefore, climate influences the conditions of comfort in most areas of the world which are affected by urbanization (Shahidan, 2011). The landforms, landscapes, and ground surfaces transform as a result; the presence of new materials and increases in constructions cause significant changes in the climate of urban areas.

The primary components of urbanization including residential, commercial and industrial developments have created several dramatic human-induced modifications to the landscape and natural ecosystem through the creation and use of impervious materials for landscaping comprising of rigid-edged rough structure blocks (Roth, 2007; Shahidan, 2011). Rapid industrialization and urbanization have caused deterioration of the urban environment. Besides, the increasing number of buildings have pushed out greenery such as trees in urban open spaces that can significantly reduce the 
negative effect of urbanization in urban areas (Santamouris et al., 2001; Shahidan, Shariff, Jones, Salleh, \& Abdullah, 2010).

A study by Karaca showed a rising trend in urban temperatures (Karaca, Tayanç, \& Toros, 1995). This is prevalent in the most urbanized, industrialized and highly populated and area of the city where these phenomena have had negative impacts on the area's regional cooling. In a different study, the findings revealed that rapid urbanization had a significant impact on the change in the regional climate in Tokyo (Karaca et al., 1995; Mochida \& Lun, 2008; Mochida et al., 1997). This gave rise to a plethora of environmental issues due to the replacement of earlier green vegetation areas, ponds, and rivers with asphalt roads, pavements, and artificial heat release, which are non-ideal ground surface conditions.

Furthermore (Ichinose, Shimodozono, \& Hanaki, 1999), urbanization produced a warm bias of $2.8^{\circ} \mathrm{C}$ based on the lowest air temperatures during 135 years' climate records (Shahidan, 2011; Tran, Uchihama, Ochi, \& Yasuoka, 2006). In a study, Akbari (2005) showed that the maximum temperatures were over $2.5^{\circ} \mathrm{C}$ higher than they were in 1920 and Washington DC, a similar experience persisted where temperatures raised by approximately $2^{\circ} \mathrm{C}$ between 1871 and 1987 (Akbari, 2005; Akbari, Menon, \& Rosenfeld, 2009). From the evidence above, it is clear that the changes brought about by urbanization led to a negative shift in the urban climate in cities around the world (Shahidan, 2011).

The built environment impact can be resulting from many factors such as the buildings construction's use of new surface materials (concrete, asphalt, tiles) and heat emissions, pollutants, and moisture. Urbanization changes the land of the surface in urban environment remarkably influencing the radiative, atmosphere, thermal, roughness, moisture and emission (Oke, Johnson, Steyn, \& Watson, 1991; Shahidan, 2011) that consequently influence the overall urban life and its quality. These transformations are described as below:

(a) Radiative modifications occur because of the presence of new surface materials that have a wide variety of albedo and emissivity principles than vegetation. Lack of shading elements such as vegetation and trees in urban space causes the radiative transformations to become uncontrollable and high that results in the increase of wall and ground surface temperatures (Shahidan, 2011).

(b) Compared to natural surfaces while the thermal mass of constructions is greater, a massive reservoir is provided for storing heat during daytime and will be released during nighttime. This procedure 
notably has a higher influence on the nighttime temperature in urban spaces. In addition, it decreases ambient temperature via evapotranspiration (Shahidan, 2011).

(c) Efficient "sealing" can cause the moisture to decrease for evapotranspiration because of surface materials replacement such as asphalt, concrete, and pavement from vegetation and natural soil, which decreases the humidity of the urban areas.

(d) The flexibility and rapid growth of barrier elements such as structures, permeability, and sharp edges can create positive and negative pressure variance on the barrier surface. This results in vortex shedding and flows separation while facing the urban airflow influencing the momentum, mass, and energy transportation away from the city areas. As a result, the instability in the city spaces will be rougher than a similar atmosphere throughout rural areas (Shahidan, 2011).

(e) The greenhouse and aerosols gases released influence the radiative change because they perform as concentration cores. Therefore, spare heat and water vapor from burning are added to the urban environment. Moreover, anthropogenic heat that is released by the fuels' combustion from stationary sources such as power generation or movable systems such as buses, cars, transportation, and animal or human metabolism act as extreme heat, increasing air temperature and warming the urban atmosphere (Roth, 2007).

\section{Thermal Comfort in Urban Microclimate}

Urban thermal comfort is defined and discussed in the context of urban climate, which reflects the dynamics in the surrounding atmosphere of a given urban setting. The growth of cities so far has turned each urban environment into a hierarchical structure of several different scales of neighborhoods, communities, and districts. The urban climate heavily affected by local configurations and resident activities, also naturally follows the same hierarchy. Generally, three different scales can be assigned to urban climate conditions.

The microscale perspective of urban climate is also commonly referred to as the microclimate. It differentiates the temperature and airflow on every surface and object, varying in very short distances. Figure 3 shows the basic spatial dimension of urban climate, which includes individual buildings, trees, 
streets, courtyards, gardens, etc. This microscopic differentiation determines that the source is dominated by immediate surfaces no greater than $0.5 \mathrm{~km}$ away, and the relevant processes are mainly radioactive, conductive and convective sensible heat fluxes from walls and grounds. Control factors contributing to the microclimate profile are naturally fabric, structure, ground cover, metabolism as well as weather and time of day or season (Adebayo, 1987). Microclimate sees its immediate applications in the studies of pedestrian bioclimatic, building, and indoor climate and practical design. As the lowest scale of urban climate, many samples can be extracted, and much detailed analysis can be conducted about relations between all of the factors and outcomes.

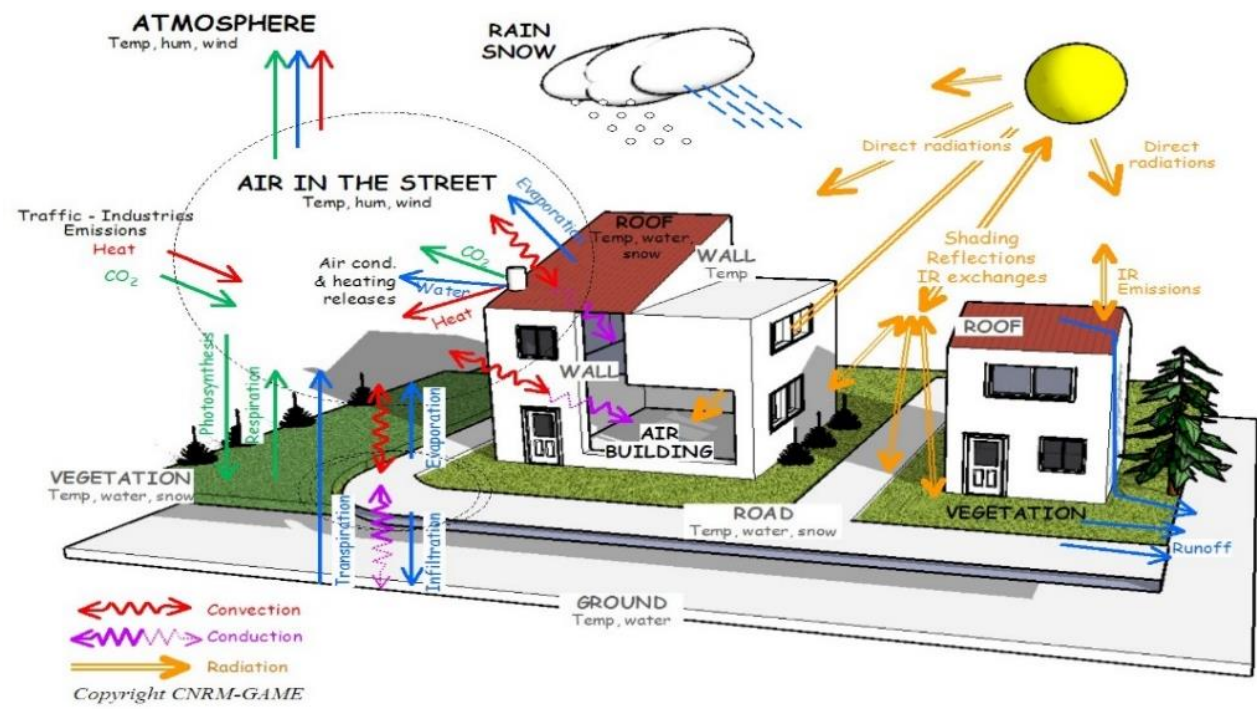

Figure 3: Three-dimensional description of microscale urban climate (Source: Adebayo [1987])

A layer beyond the micro scale of urban climate, the local scale examines the climate of neighborhoods in cities with similar urban development (surface cover, size, and spacing of buildings, activities, etc.). The standard climate station can be designed to monitor the local-scale urban climate. By definition, the local-scale signals are an integration of microclimate effects and typical spatial dimensions extending from one to several kilometers. Figure 4 shows a representative Urban Climate Zone (UCZ), an Air Temperature $(\mathrm{Ta})$ measurement which usually comes from either climate stations or at the top of the Roughness Sub Layer (RSL) where turbulent 
mixing leads to sufficient blending of microscale effects (Barlow, 2014; Oke, 2002). In studying the local-scale climate, heat fluxes from roofs, chimneys and the spatial average of surface-air volume should be considered. While weather and time of day or season also play a role in the micro-scale, the horizontal extent of UCZ should be controlled. Discussions of the local-scale urban climate could result in interesting applications regarding neighborhood climate and more sustainable urban design. This scale serves as a transition from the microscale environment to the whole city perspective and is correlated with both the smaller and the larger scales environment.

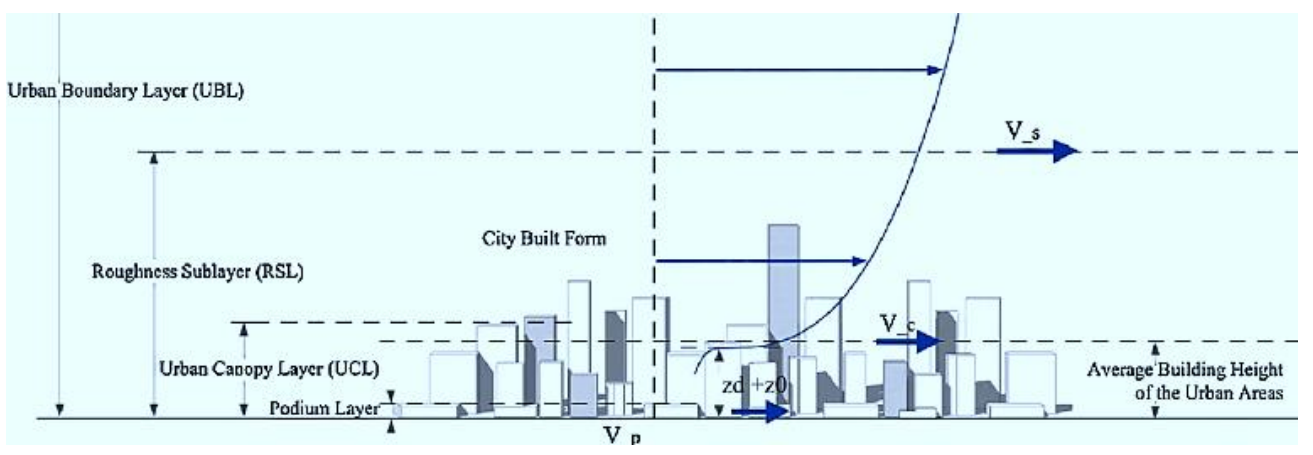

Figure 4: Example subject area of the local scale urban climate

(Source: Shi, Ren, Zheng, and Ng [2016])

Stepping up from the neighborhood level to the whole city, a spatial dimension typically appears covering tens of kilometers. This so-called mesoscale of urban climate is affected by both the city itself and the surrounding area. New processes that have to be considered in this scale include heat fluxes from the top of the RSL, entrainment of heat from above the Urban Boundary Layer (UBL), air mass advection from upwind, internal radioactive flux divergence, etc. as indicated in Figure 5. The vast scale also makes much more control factors relevant - city horizontal and vertical dimensions, weather and time of day, seasonal plant growth, snow cover, soil wetness, and space heating/cooling and emissions as a few examples. Applications of the mesoscale urban climate research can be found in UHI mitigation for heat waves, photochemistry of urban plume, suppression of storms, planning of urban layout as well as many other fruitful areas (Oke, 2002). From the policy and strategy perspectives, the three scales of urban climate also lead to natural classifications. 

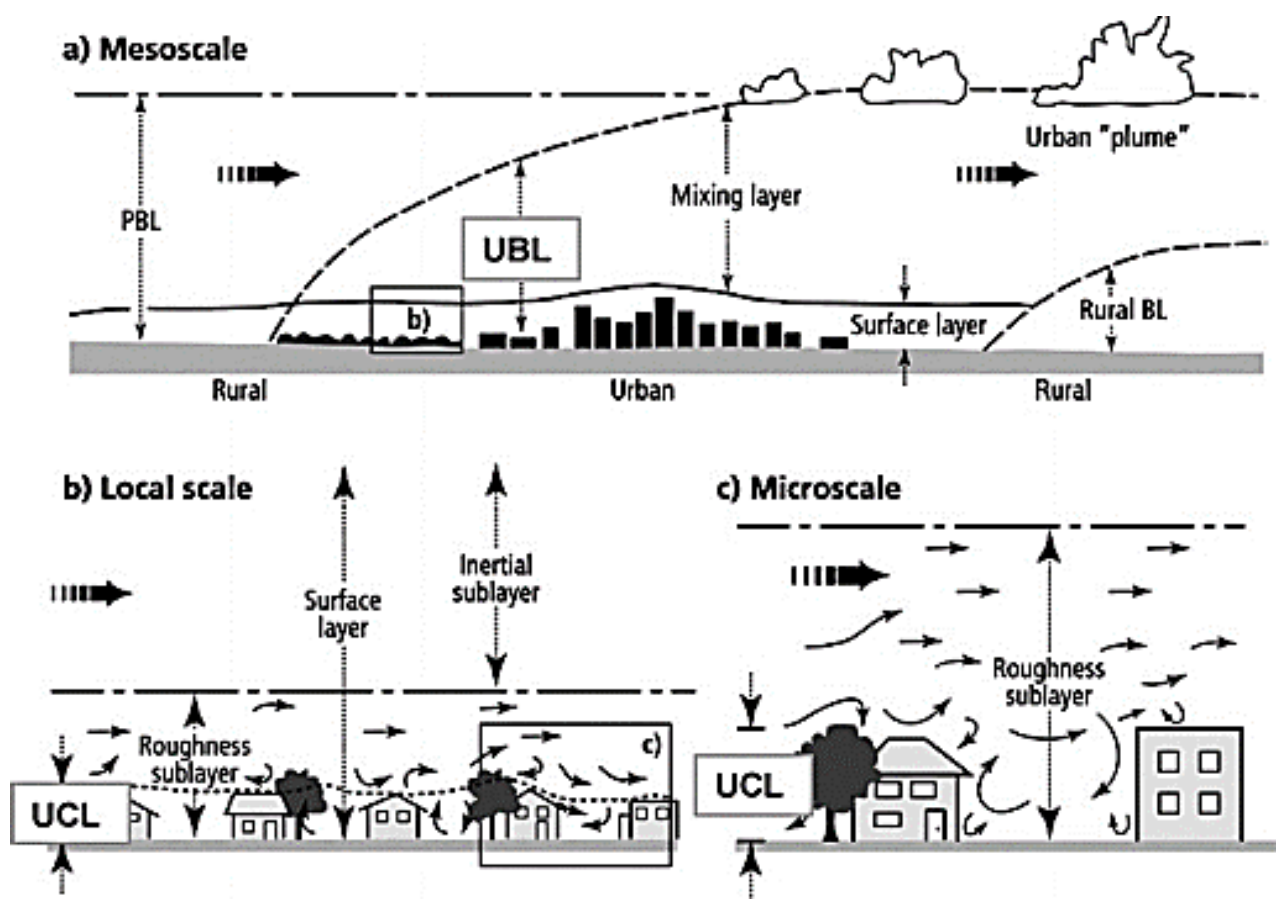

Figure 5: Schematic diagram of the urban boundary layer (UBL)

(Source: Oke [2002])

\section{Methodology for Thermal Comfort Evaluation of Urban Open Space}

Although the microclimatic conditions could significantly influence thermal comfort and the usage of urban open spaces, most of the time, it is clear that the physiological sensation is still considered a necessary but not sufficient factor. The discrepancy between the subjective thermal sensation and objective calculation has been seen as a common situation; people's comfort level in the urban open spaces is responding to microclimate could not be explained by physiological parameters all the time. It has been seen that the thermal comfort evaluation of urban open space would not only be contributed by physiological sensation but also require other psychological factors such as expectation and satisfaction (Höppe, 2002).

Recent studies identified PET as the most suitable choice for assessing the thermal comfort conditions of an outdoor environment (Höppe, 1999; Makaremi, Salleh, Jaafar, \& GhaffarianHoseini, 2012). This is due to the consideration of the interrelation between the human body's energy balance and short- and longwave radiation (Lin, Matzarakis, \& Hwang, 2010). In the 
thermal comfort evaluation from the energy fluxes between the atmosphere and the body, versatile thermal indices is improved such as effective temperature (ET), predicted mean vote (PMV) (Fanger, 1970; Hwang, Lin, \& Matzarakis, 2011; Makaremi et al., 2012), standard effective temperature (SET) for internal use (Gagge, Fobelets, \& Berglund, 1986; T.-P. Lin et al., 2010; Makaremi et al., 2012), OUT_SET (Pickup \& de Dear, 2000; Spagnolo \& de Dear, 2003) and physiologically equivalent temperature (PET) (Höppe, 1999; Makaremi et al., 2012) for external use. The process of estimating the PET is shown in Figure 6.

Modelling of Mean Radiant Temperature within urban structures Estimation of Thermal Indices

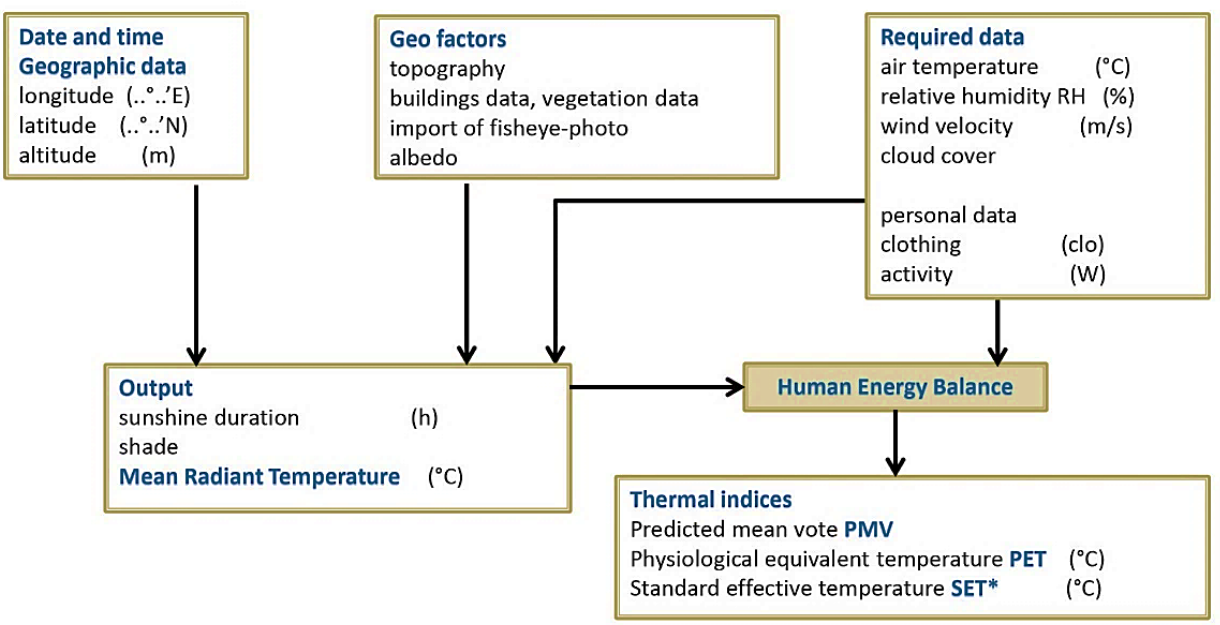

Figure 6: Rayman analysis procedure

(Sources: Höppe [1999]; Makaremi et al. [2012])

PET is the physiological equivalent temperature at any spaces such as indoors or outdoors. The human bodies' heat balance is maintained with the skin and core temperatures the same as those under the situations being measured (Makaremi et al., 2012). This PET enables a layperson to compare the integral effects of complex thermal conditions outside of the experience indoors (Höppe, 1999). The PET's thermal comfort standards can also be changed for various climate areas (Lin \& Matzarakis, 2008; Matzarakis \& Mayer, 1996). PET furthermore, can be analyzed using the Rayman model which is used in urban built-up spaces and able to predict thermal comfort in outdoor spaces (Gulyás, Unger, \& Matzarakis, 2006; Matzarakis, Rutz, \& Mayer, 2007). PET can also evaluate relative humidity, Tmrt, temperature, 
wind speed, human activity, and clothing in the model with ease. Additionally, the Rayman model is also used to calculate the ratio of free skyspaces to the whole fisheye view at some locations, which is known as the SVF (sky view factor). Therefore, PET agrees with human thermal comfort range values which are between $22^{\circ} \mathrm{C}$ and $34^{\circ} \mathrm{C}$ whereas a relatively wider "acceptable range" is for neutral, slightly cool and slightly warm (Table 1).

Table 1: Thermal Perceptions Classification (TPC) for Temperate Region and (Sub) Tropical Region

\begin{tabular}{lccl}
\hline $\begin{array}{c}\text { Thermal } \\
\text { perception }\end{array}$ & $\begin{array}{c}\text { TPC (sub) } \\
\text { tropical region a } \\
\left({ }^{\circ} \text { C PET) }\right.\end{array}$ & $\begin{array}{c}\text { TPC for temperate } \\
\text { region } \text { b } \\
\text { ('C PET) }\end{array}$ & \multicolumn{1}{c}{$\begin{array}{c}\text { Sensation } \\
\text { of human }\end{array}$} \\
\hline Very cold & $<14$ & $<4$ & Much too cool \\
Cold & $14-18$ & $4-8$ & Too cool \\
Cool & $18-22$ & $8-13$ & Comfortably cool \\
Slightly cool & $22-26$ & $13-18$ & comfortable \\
Neutral & $26-30$ & $18-23$ & Comfortably warm \\
Slightly warm & $30-34$ & $23-29$ & Too warm \\
Warm & $34-38$ & $29-35$ & Much too warm \\
\hline Hot & $38-42$ & $35-41$ & \\
Very hot & $<42$ & $<41$ & \\
\hline
\end{tabular}

Sources: Lin \& Matzarakis (2008); Matzarakis \& Mayer (1996).

\section{Environmental Factors Influencing Thermal Comfort}

Human body heat balance and the environmental situations that allow the balance should be found out to obtain thermal comfort. These environmental situations are described as the followings:

(a) Air temperature $\left({ }^{\circ} \mathrm{C}\right)$ : The body heat is lost to the air by convection. The body tends to gain heat from the environment when the air temperature is above $37^{\circ} \mathrm{C}$. The comfort range for the majority of people is from $20^{\circ} \mathrm{C}$ in winter to $25^{\circ} \mathrm{C}$ in summer (Lechner, 2014).

(b) Air velocity (feet/minute): Air movement influences the rare of heat-loss through evaporation and convection. The comfortable range is from approximately 95 to approximately 130 feet/minute (fpm) (Lechner, 2014). 
(c) Relative Humidity: It is a ratio of atmospheric moisture present amount in relation to the presented amount when the air is saturated. Relative humidity is a function of temperature and content moisture because the latter amount is reliant on temperature (Gagge et al., 1986). Thus, relative humidity itself does not directly show the real amount of atmospheric moisture present. The comfortable range of $\mathrm{RH}$ is above $20 \%$ all year, below $80 \%$ in winter and below $60 \%$ in the summer.

(d) Mean radiant temperature (Tmrt): It is the uniform surface temperature of an unreal black inclusion. Human exchanges the same heat by radiation in the real situation (American Society of Heating, Refrigerating and AirConditioning Engineers, 2009). The Tmrt of an environment is the measure of the combined influence of surfaces temperatures through that environment. The bigger surface area and its surround have more influence on the temperature of the surface.

(e) Physical Activity (Tme): Metabolism is the motor of the human body, and the amount of its released energy is dependent on the amount of muscular activity. For maintaining thermal comfort, physical activity plays an important role for example; the amount of heat that is generated by an active person is approximately six times more than a heat that is generated by a resting person. An activity level of a resting person is $0.8 \mathrm{Tme}$, and it is 1 Tme for sitting person while this amount is 8 Tme for a jogging person (American Society of Heating, Refrigerating and Air-Conditioning Engineers, 2009).

(f) Clothing (CLO): It is a thermal resistance that decreases the heat of the body loss and keeps the body from cold. CLO is categorized based on its protection value. In general, a high CLO value is 1.5 which indicate a heavy coat while a 0 CLO value specifies a nude person (American Society of Heating, Refrigerating and Air-Conditioning Engineers, 2009).

(g) Activity: Activity level influences energy production in the human body and can considerably affect the comfort level. Mets express activity level: each met is the metabolic rate of a seated, relaxed adult and equals $58 \mathrm{~W} / \mathrm{m} 2$ (Clark \& Edholm, 1985). Different types of activities with the relevant metabolic rates are shown in Table 2. Some activities such as hard physical work or sports may produce conditions that cause thermal discomfort. For example, an outdoor thermal condition that is comfortable for activity such as walking can be uncomfortable for running. This is due to the surplus of energy added to the energy budget of the body. Therefore, one may take action such as removing 
some clothing. Another option is providing an appropriate design for running paths, which allows suitable thermal conditions for running.

Table 2: Metabolic Rates of Different Activities (ISO7730, 2005)

\begin{tabular}{|l|c|c|}
\hline Activity & W/m² & Met \\
\hline Reclining & 46 & 0.8 \\
Seated, relaxed & 58 & 1.0 \\
Sedentary activity & & \\
(Office, dwelling school, laboratory) & 70 & 1.2 \\
$\begin{array}{l}\text { Standing, light activity } \\
\text { (shopping, laboratory, light industry) }\end{array}$ & 93 & 1.6 \\
Standing, medium activity & & \\
(shop assistant, domestic work, & & 2.0 \\
machine work) & 116 & \\
Walk on level: & & 1.9 \\
$2 \mathrm{~km} / \mathrm{h}$ & 110 & 2.4 \\
$3 \mathrm{~km} / \mathrm{h}$ & 140 & 3.8 \\
$4 \mathrm{~km} / \mathrm{h}$ & 165 & 3.4 \\
$5 \mathrm{~km} / \mathrm{h}$ & 200 & \\
\hline
\end{tabular}

\section{Outdoor Thermal Comfort and the Comfort Zones}

The thermal environment influences People's outdoor thermal comfort while its use is dependent on their observation of outdoor thermal environments (Eliasson, Knez, Westerberg, Thorsson, \& Lindberg, 2007; Hwang et al., 2011; Lin, 2009; Nikolopoulou, Baker, \& Steemers, 2001; Thorsson, Lindqvist, \& Lindqvist, 2004). Besides, outdoor thermal spaces are considerably influenced by the design of built environment (Hussin, Hamid, Zain, \& Rahman, 2010; Hwang \& Lin, 2007; Wong et al., 2007). Researches in the last decade have focused on determining the comfort levels in the internal environment leading to an unintentional lack of focus on thermal comfort in urban outdoor environments especially in light of the increasing UHI effect in urban areas. Conventional comfort theory which focused mainly on the internal environment depends on a model of steady-state where the produced heat is equal to lost heat in the area to maintain the temperature of core body at $37^{\circ} \mathrm{C}$ thereby creating the environmental situations that offer thermal satisfaction based on the subjects activity and their CLO level that decreases in a narrow band (Nikolopoulou et al., 2001). Although some models present a similar scenario for the outdoor environment, they often neglect external influences such as the surface materials and presence of vegetative covers. Many studies investigating shading effects on the outdoor thermal environments found that shading is able to prevent direct solar radiation (Hussin et al., 2010). 
Thermal comfort comes from a careful balance of air movement, humidity, temperature and mean radiant temperature. Clothing and physical activity are secondary factors that should be considered when designing for thermal comfort. These combinations of air temperature and relative humidity are plotted on the psychometric chart, which is defined as a comfort zone. Comfort zone is an area on the psychometric chart that defines the circumstances that most people would be comfortable. As the psychometric chart relates only relative humidity and temperature, the other two factors of MRT and air velocity are fixed. The air velocity is assumed modest, and the MRT is assumed to be close to the temperature of the surrounding air.

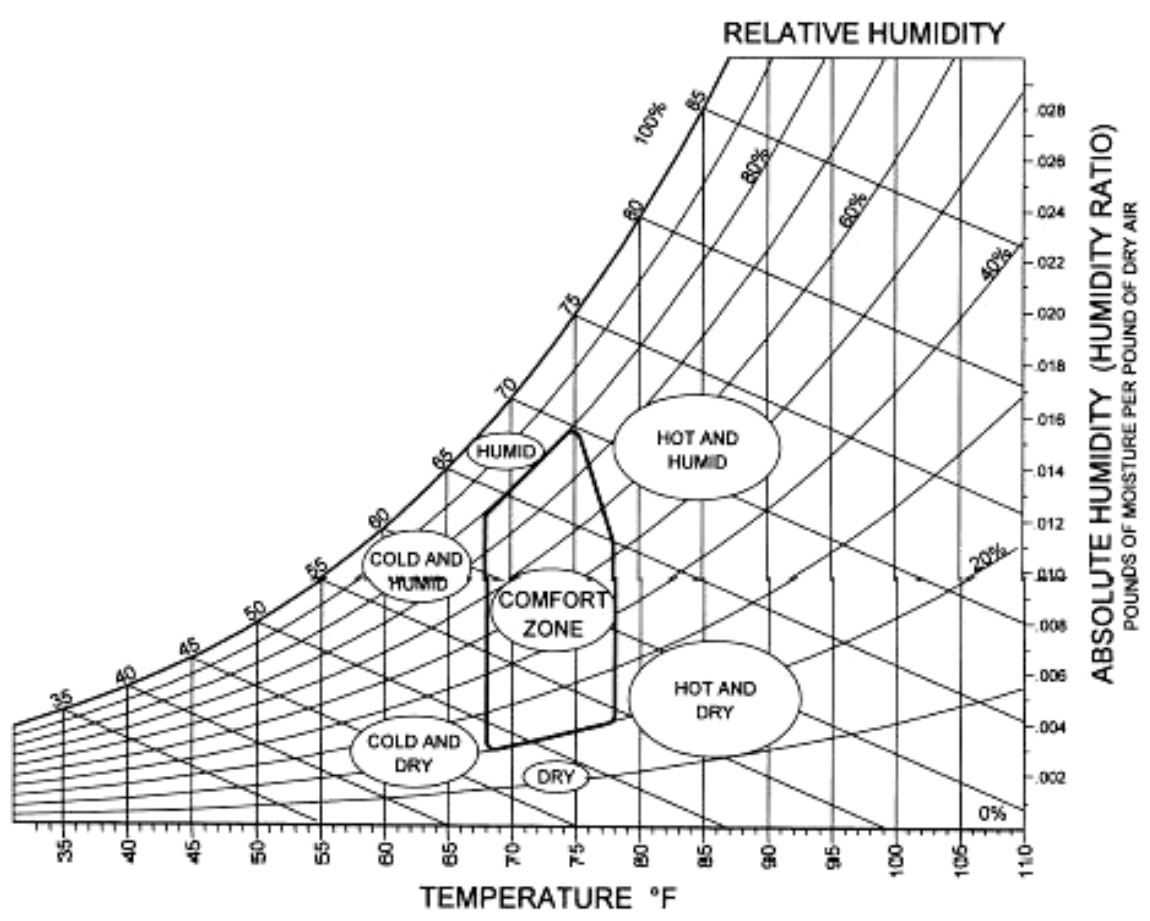

Figure 7: the Psychometric chart shows the comfort zone

(Source: Poonam [2005])

The comfort zone is not fixed and varies based on time of the year, culture, health, physical activity and the amount of clothing (Lechner, 2014). The comfort zone contains the factors that influence thermal comfort. Air movements up to a certain point can reduce high temperatures, which is not enough and should be enhanced by other strategies. The comfort zone can adjust it where one factor transformed to restore thermal comfort, which is 
achieved with a few adjustments in the thermal situations. The comfort zone borders are not fixed and change with personal preferences, climate, place, people, and culture as shown in Figure 7.

\section{The Research Gap}

The complexity of the external built environment depends on variability, spatially and temporally, and the variety of peoples' activities. Studies on grasping outdoor thermal comfort conditions, however, were primarily restricted to temperate areas (Makaremi et al., 2012; Nikolopoulou \& Lykoudis, 2007). Accordingly, there is a considerable lack of research on the importance of human thermal comfort and material of outdoor thermal situations to enhance urban quality in hot and humid climates (Lin, 2009; Makaremi et al., 2012). Therefore, more research on human comfort situations in outdoor environments in tropical climates related to the certain climate and ground surface conditions as well as the human parameters and the particular subjective responses is needed. In hot and humid climates, the radiant temperature is the crucial factor in human comfort (Lewis Jr., Nicholas, Scales, \& Woollum, 1971; Plumley, 1977). One of the main human discomforts in the tropical climate depends on the radiation regime (Emmanuel, 2005) for example, the high level of solar radiation during the year which becomes worse during dry and hot seasons while a UHI is maximum. Therefore, in the urban spaces, the radiant temperature is different according to urban canyon geometry, shading, seasons, and vegetation availability. This variation is mainly due to the amount of global radiation, which is received, from the ground surface and the variances for radiation by the person. Consequently, the lack and presence of these factors cause a UHI effect that in turn causes extreme variation in the human thermal comfort of tropical climates.

The majority of researches relevant to outdoor thermal comfort which has been done in the Asian region focused on Taiwan. Hwang \& Lin (2007) for example, conducted a study to investigate the outdoor thermal comfort range for Taiwanese people (Hwang \& Lin, 2007). Additionally, there are other areas considered for outdoor thermal comfort researches and studies such as school campus (Shih, Lin, Tan, \& Liu, 2017), urban parks (Lin, Lin, \& Hwang, 2013), public square (Huang, Lin, \& Lien, 2015; Lin, 2009) and a rural traditional settlement (Yang \& Lin, 2016) based on the current climate conditions. In Taiwan generally, the thermal air temperature increase rate is $0.81^{\circ} \mathrm{C}$ every 25 years in the plain area under the climate change influence (Lin et al., 2015). Despite the relatively large volume of thermal comfort researches conducted in 
Malaysia, their focus is very limited and certainly did not look at thermal comfort in urban villages. For example, Sheikh Ahmad Zaki (2017) conducted a comparative study on student's adaptive behavior and comfort of temperature at UTM in Malaysia and Kyushu University in Japan. Results show the mean operative temperature in Japan was $25.1^{\circ} \mathrm{C}$ in the free running model (FR). In contrast, Malaysia was $25.6^{\circ} \mathrm{C}$. Also, the mean operative temperature in the mechanical cooling model $(\mathrm{CL})$ were $25.6^{\circ} \mathrm{C}, 26.2^{\circ} \mathrm{C}$ in Malaysia and Japan respectively (Jomehzadeh et al., 2017).

As mentioned above, there is particularly a lack of studies evaluating thermal comfort in urban villages in the context of Kuala Lumpur and other Malaysian cities generally. It is important to investigate the thermal comfort in these areas because (i) these sites are rich in culture and heritage values; and (ii) a significant percentage of population occupies these areas because of its lower cost of accommodation. They created a community in need of functional outdoor spaces to improve the quality of life and; (iii) these areas are primarily covered with vegetation, and the vegetation is significantly capable of cooling the surrounding microclimate and can be used as a thermal comfort strategy in key areas in the urban center. Also, most of them have successfully maintained the characteristics of the traditional village called the 'kampung.' Therefore, redevelopment in these areas has been restricted in an attempt to maintain the cultural and social values of the place. With a strong commitment from the government, a comprehensive development master plan was prepared for urban villages like Kampung Baru, Kampung Sungai Penchala, and Kampung Melayu Kepong in Kuala Lumpur. Despite the resistance, it seems preventing urban development in urban villages is inevitable on the current track. A strong incentive is needed by the government to maintain many existing characteristics within the status in these areas particularly those that help mitigate the UHI effect namely the large percentage of vegetative cover.

\section{Conclusion}

This paper reported a description about urbanization in the global scale and in Malaysia as well. It also explained how urban villages appeared in the modern urbanized areas such as Kuala Lumpur. Theoretically, the review of the related researches presented in this chapter demonstrates that vegetation and ground materials could be changed and affect the urban microclimate areas. They potentially modify the UHI influence by decreasing air temperature, decreasing building energy utilization, and affecting human thermal comfort. 
These strategies contain an arrangement of a higher percentage of vegetative cover and other material with higher albedo values to classify physical properties, for example; types of surface, color material, and structure that could increase the cooling effect in urban environments. The entire influence of both changes will provide better shading quality, radiation filtration, and promote important growths in the evapotranspiration. The important modification to the microclimatic situations increases the 'oasis effect' in cities that results in better energy savings and better outdoor thermal comfort. Therefore, more evaluation and measures will be needed to prove the effect on the urban spaces, especially in the tropics climates in future study.

\section{Acknowledgments}

It was an overwhelming experience to work under the University of Malaya grant no: RP026C-15SBS.

\section{References}

Adebayo, Y. R. (1987). Land-use approach to the spatial analysis of the urban 'heat island'in Ibadan, Nigeria. Weather, 42(9), 273-280.

Akbari, H. (2005). Energy saving potentials and air quality benefits of urban heat island mitigation. Lawrence Berkeley National Laboratory. Retrieved from https://escholarship.org/uc/item/4qs5f42s

Akbari, H., Menon, S., \& Rosenfeld, A. (2009). Global cooling: Increasing world-wide urban albedos to offset $\mathrm{CO}_{2}$. Climatic Change, 94(3), 275-286.

Al-mulali, U., Sab, C. N. B. C., \& Fereidouni, H.G. (2012). Exploring the bidirectional long run relationship between urbanization, energy consumption, and carbon dioxide emission. Energy, 46(1), 156-167.

Allaby, M., \& Park, C. (2013). A dictionary of environment and conservation. Oxford: Oxford University Press.

American Society of Heating, Refrigerating and Air-Conditioning Engineers. (2009). 2009 ASHRAE handbook: Fundamentals. Atlanta: American Society of Heating, Refrigerating and Air-Conditioning Engineers.

Barlow, J. F. (2014). Progress in observing and modelling the urban boundary layer. Urban Climate, 10, 216-240.

Carr-Hill, R. A. (1992). Health related quality of life measurement-Euro style. Health Policy, 20(3), 321-328. 
Christensen, A. J. (2005). Dictionary of landscape architecture and construction. New York: McGraw-Hill.

Chung, H. (2010). Building an image of villages-in-the-city: A clarification of china's distinct urban spaces. International Journal of Urban and Regional Research, 34(2), 421-437.

Clark, R., \& Edholm, O. G. (1985). Man and his thermal environment. London: Edward Arnold.

Eliasson, I., Knez, I., Westerberg, U., Thorsson, S., \& Lindberg, F. (2007). Climate and behaviour in a Nordic city. Landscape and Urban Planning, 82(1), 72-84.

Elsayed, I. S. (2012). Mitigation of the urban heat island of the city of Kuala Lumpur, Malaysia. Middle-East Journal of Scientific Research, 11(11), 16021613.

Emmanuel, R. (2005). Thermal comfort implications of urbanization in a warmhumid city: The Colombo Metropolitan Region (CMR), Sri Lanka. Building and Environment, 40(12), 1591-1601.

Evans, G. W. (Ed.). (1984). Environmental stress. Cambridge: Cambridge University Press.

Fanger, P. O. (1970). Thermal comfort. Analysis and applications in environmental engineering. Copenhagen: Danish Technical Press.

Gagge, A. P., Fobelets, A., \& Berglund, L. (1986). A standard predictive index of human response to the thermal environment. ASHRAE Trans., 92(2B), 709-731.

Gehl, J., \& Gemzøe, L. (2004). Public spaces, public life. Copenhagen: The Danish Architectural Press.

Gulyás, Á., Unger, J., \& Matzarakis, A. (2006). Assessment of the microclimatic and human comfort conditions in a complex urban environment: Modelling and measurements. Building and Environment, 41(12), 17131722.

Hao, P. (2015). The effects of residential patterns and Chengzhongcun housing on segregation in Shenzhen. Eurasian Geography and Economics, 56(3), 308330.

Hao, P., Geertman, S., Hooimeijer, P., \& Sliuzas, R. (2013). Spatial analyses of the urban village development process in Shenzhen, China. International Journal of Urban and Regional Research, 37(6), 2177-2197.

Höppe, P. (1999). The physiological equivalent temperature-a universal index for the biometeorological assessment of the thermal environment. International Journal of Biometeorology, 43(2), 71-75. 
Höppe, P. (2002). Different aspects of assessing indoor and outdoor thermal comfort. Energy and buildings, 34(6), 661-665.

Huang, K.-T., Lin, T.-P., \& Lien, H.-C. (2015). Investigating thermal comfort and user behaviors in outdoor spaces: A seasonal and spatial perspective. Advances in Meteorology, 2015, 4-14.

Hussin, M., Hamid, M., Zain, Z., \& Rahman, R. (2010). An evaluation data of solar irradiation and dry bulb temperature at Subang under Malaysian climate. Paper presented at the Control and System Graduate Research Colloquium (ICSGRC), Shah Alam, Malaysia, 22 June.

Hwang, R.-L., \& Lin, T.-P. (2007). Thermal comfort requirements for occupants of semi-outdoor and outdoor environments in hot-humid regions. Architectural Science Review, 50(4), 357-364.

Hwang, R.-L., Lin, T.-P., \& Matzarakis, A. (2011). Seasonal effects of urban street shading on long-term outdoor thermal comfort. Building and Environment, 46(4), 863-870.

Ichinose, T., Shimodozono, K., \& Hanaki, K. (1999). Impact of anthropogenic heat on urban climate in Tokyo. Atmospheric Environment, 33(24), 38973909.

Jomehzadeh, F., Nejat, P., Calautit, J. K., Yusof, M. B. M., Zaki, S. A., Hughes, B. R., \& Yazid, M. N. A. W. M. (2017). A review on windcatcher for passive cooling and natural ventilation in buildings, Part 1: Indoor air quality and thermal comfort assessment. Renewable and Sustainable Energy Reviews, 70, 736-756.

Karaca, M., Tayanç, M., \& Toros, H.n. (1995). Effects of urbanization on climate of Istanbul and Ankara. Atmospheric Environment, 29(23), 3411-3421.

Lechner, N. (2014). Heating, cooling, lighting: Sustainable design methods for architects. Hoboken, New Jersey: John Wiley \& Sons.

Lewis Jr., J. E., Nicholas, F. W., Scales, S. M., \& Woollum, C. A. (1971). Some effects of urban morphology on street level temperatures at Washington, D.C. Journal of the Washington Academy of Sciences, 61(4), 258-265.

Lin, C.-H., Lin, T.-P., \& Hwang, R.-L. (2013). Thermal comfort for urban parks in subtropics: Understanding visitor's perceptions, behavior and attendance. Advances in Meteorology, 2013, 1-8.

Lin, C. Y., Chua, Y. J., Sheng, Y. F., Hsu, H. H., Cheng, C. T., \& Lin, Y. Y. (2015). Altitudinal and latitudinal dependence of future warming in Taiwan simulated by WRF nested with ECHAM5/MPIOM. International Journal of Climatology, 35(8), 1800-1809. 
Lin, T.-P. (2009). Thermal perception, adaptation and attendance in a public square in hot and humid regions. Building and Environment, 44(10), 20172026.

Lin, T.-P., \& Matzarakis, A. (2008). Tourism climate and thermal comfort in Sun Moon Lake, Taiwan. International Journal of Biometeorology, 52(4), 281290.

Lin, T.-P., Matzarakis, A., \& Hwang, R.-L. (2010). Shading effect on long-term outdoor thermal comfort. Building and Environment, 45(1), 213-221.

Makaremi, N., Salleh, E., Jaafar, M. Z., \& GhaffarianHoseini, A. (2012). Thermal comfort conditions of shaded outdoor spaces in hot and humid climate of Malaysia. Building and Environment, 48, 7-14.

Matzarakis, A., \& Mayer, H. (1996). Another kind of environmental stress: Thermal stress. NEWSLETTERS No. 18, WHO Collaborating Centre for Air Quality Management and Air Pollution Control, pp. 7-10. Retrieved from

https://www.researchgate.net/publication/233759000_Another_kind_of_e nvironmental_stress_Thermal_stress

Matzarakis, A., Rutz, F., \& Mayer, H. (2007). Modelling radiation fluxes in simple and complex environments-application of the Rayman model. International Journal of Biometeorology, 51(4), 323-334.

Mochida, A., \& Lun, I. Y. (2008). Prediction of wind environment and thermal comfort at pedestrian level in urban area. Journal of Wind Engineering and Industrial Aerodynamics, 96(10), 1498-1527.

Mochida, A., Murakami, S., Ojima, T., Kim, S., Ooka, R., \& Sugiyama, H. (1997). CFD analysis of mesoscale climate in the Greater Tokyo area. Journal of Wind Engineering and Industrial Aerodynamics, 67, 459-477.

Nikolopoulou, M., \& Lykoudis, S. (2007). Use of outdoor spaces and microclimate in a Mediterranean urban area. Building and Environment, 42(10), 3691-3707.

Nikolopoulou, M., Baker, N., \& Steemers, K. (2001). Thermal comfort in outdoor urban spaces: Understanding the human parameter. Solar Energy, 70(3), 227-235.

Oke, T. R. (2002). Boundary layer climates. New York: Routledge.

Oke, T. R., Johnson, G. T., Steyn, D. G., \& Watson, I. D. (1991). Simulation of surface urban heat islands under 'ideal' conditions at night part 2: Diagnosis of causation. Boundary-Layer Meteorology, 56(4), 339-358.

Pickup, J., \& de Dear, R. (2000). An outdoor thermal comfort index (OUT_SET*)-Part I-the model and its assumptions. In de Dear, R., Kalma, J., Oke, T., \& Auliciems, A. (Eds.), Biometeorology and urban climatology at 
the turn of the millennium (pp. 279-283). Geneva: World Meteorological Organization.

Plumley, H. J. (1977). Design of outdoor urban spaces for thermal comfort. In G. M. Heisler \& L. P. Herrington (Eds.), Proceedings of the Conference on Metropolitan Physical Environment: Use of vegetation, space, and structures to improve amenities for people (pp. 152-162). Upper Darby, PA: U.S. Department of Agriculture, Forest Service, Northeastern Forest Experiment Station.

Poonam, A. D. (2005). Outdoor thermal comfort analysis for the Dhond residence in Goa, India. Master's thesis, University of Arizona, Tucson, United States of America.

Radhi, H., Sharples, S., \& Assem, E. (2015). Impact of urban heat islands on the thermal comfort and cooling energy demand of artificial islands-a case study of Amwaj Islands In Bahrain. Sustainable Cities and Society, 19, 310318.

Ren, L., Wang, W., Wang, J., \& Liu, R. (2015). Analysis of energy consumption and carbon emission during the urbanization of Shandong Province, China. Journal of Cleaner Production, 103, 534-541.

Roth, M. (2007). Review of urban climate research in (sub) tropical regions. International Journal of Climatology, 27(14), 1859-1873.

Saleh, Y., Hashim, M., Mahat, H., \& Nayan, N. (2016). Transformation of urban villages: Preliminary findings on the wellbeing of small city residents in the fringe of Malaysian metropolitan region. International Journal of Academic Research in Business and Social Sciences, 6(12), 518-529.

Salleh, K.O., \& Ghaffar, F.A. (2000). Environmental decay and the urban poor in Southeast Asia: A study of the Klang river. JATI-Journal of Southeast Asian Studies, 5, 1-15.

Sani, S. (1990). Urban climatology in Malaysia: An overview. Energy and Buildings, 15(1-2), 105-117.

Santamouris, M., Papanikolaou, N., Livada, I., Koronakis, I., Georgakis, C., Argiriou, A., \& Assimakopoulos, D. (2001). On the impact of urban climate on the energy consumption of buildings. Solar Energy, 70(3), 201216.

Shahidan, M. F. (2011). The potential optimum cooling effect of vegetation with ground surface physical properties modification in mitigating the urban heat island effect in Malaysia. Ph.D. thesis, Welsh School of Architecture, Cardiff University, Cardiff, United Kingdom.

Shahidan, M. F., Shariff, M. K., Jones, P., Salleh, E., \& Abdullah, A. M. (2010). A comparison of Mesua Ferrea L. and Hura Crepitans L. for shade creation 
and radiation modification in improving thermal comfort. Landscape and Urban Planning, 97(3), 168-181.

Shi, Y., Ren, C., Zheng, Y., \& Ng, E. (2016). Mapping the urban microclimatic spatial distribution in a sub-tropical high-density urban environment. Architectural Science Review, 59(5), 370-384.

Shih, W.-M., Lin, T.-P., Tan, N.-X., \& Liu, M.-H. (2017). Long-term perceptions of outdoor thermal environments in an elementary school in a hothumid climate. International Journal of Biometeorology, 61(9), 1657-1666.

Spagnolo, J., \& de Dear, R. (2003). A field study of thermal comfort in outdoor and semi-outdoor environments in subtropical Sydney Australia. Building and Environment, 38(5), 721-738.

Thorsson, S., Lindqvist, M., \& Lindqvist, S. (2004). Thermal bioclimatic conditions and patterns of behaviour in an urban park in Göteborg, Sweden. International Journal of Biometeorology, 48(3), 149-156.

Tran, H., Uchihama, D., Ochi, S., \& Yasuoka, Y. (2006). Assessment with satellite data of the urban heat island effects in Asian mega cities. International Journal of Applied Earth Observation and Geoinformation, 8(1), 34-48.

Ujang, N., \& Aziz, F. A. (2016). The Malay enclave of Kampong Bharu as a living tradition: A place of uncertainty. Environment-Behaviour Proceedings Journal, 1(2), 197-202.

UNPD. (2014). World urbanization prospects: The 2014 revision: United Nations Population Division New York, New York, USA.

Wang, Y., Chen, L., \& Kubota, J. (2016). The relationship between urbanization, energy use and carbon emissions: Evidence from a panel of Association of Southeast Asian Nations (ASEAN) countries. Journal of Cleaner Production, 112, 1368-1374.

Wong, N. H., Jusuf, S. K., La Win, A. A., Thu, H. K., Negara, T. S., \& Xuchao, W. (2007). Environmental study of the impact of greenery in an institutional campus in the tropics. Building and Environment, 42(8), 29492970.

Yang, S.-R., \& Lin, T.-P. (2016). An integrated outdoor spaces design procedure to relieve heat stress in hot and humid regions. Building and Environment, 99, 149-160. 